\title{
A comparison of model estimates of ocean-tide loading displacements in New Zealand
}

Research Article

\author{
V. Gladkikh, R. Tenzer
}

National School of Surveying, Division of Sciences, University of Otago, 310 Castle street, Dunedin, New Zealand

\begin{abstract}
:
We analyze the regional accuracy of the global ocean tide models TPXO7.2, GOT00.2, NAO.99b, FES2004, and EOT10a using the tide-gauge records from 7 stations along the coastline of New Zealand. The comparison reveals that TPXO7.2 provides the bestfit with the tide-gauge data in this part of the world. The TPXO.7.2 ocean tide model is then used for computing and analysis of the vertical and horizontal ocean-tide loading displacements in New Zealand. The ocean-tide loading is calculated for the semi-diurnal and diurnal tidal harmonic constituents $M_{2}, S_{2}, N_{2}, K_{2}, K_{1}, O_{1}, P_{1}$, and $Q_{1}$, the long-period tidal components $M_{f}$ and $M_{m}$, and for the shallow-water (nonlinear) components $\mathrm{M}_{4}, \mathrm{MS}_{4}$, and $\mathrm{MN}_{4}$. The charts of the ocean tide (offshore) and the ocean-tide loading (onshore) are compiled on a $5 \times 5$ arc-min geographical grid at the study area of New Zealand. The results reveal that the major contribution to the ocean-tide loading displacements up to a few centimeters is attributed to the semi-diurnal and diurnal harmonic constituents. The contribution of the long-period tidal components is to about $1 \mathrm{~mm}$, and the effect of the shallow-water components is less than $0.2 \mathrm{~mm}$. The maxima of vertical and horizontal displacements are typically of the same order of magnitude with larger amplitudes of vertical motions. The maximum amplitudes of vertical motions up to $5.6 \mathrm{~cm}$ are found in the upper north region of the North Island. The maximum horizontal motions up to $2.1 \mathrm{~cm}$ are in the northwest part of the South Island The ocean-tide loading displacements in New Zealand are finally compared with the crustal deformations due to geodynamic, atmospheric and other phenomena.
\end{abstract}

\section{Keywords:}

Crustal motion $\cdot$ Green's functions $\cdot$ loading $\cdot$ Love numbers $•$ ocean tide

(c) Versita Warsaw and Springer-Verlag Berlin Heidelberg.

Received 6 December 2010; accepted 17 January 2011

\section{Introduction}

The Earth tide is the crust displacement as a direct response to the gravitational attraction of the Moon and Sun. The ocean tide is the ocean mass redistribution as a direct response of the ocean to the gravitational attraction of the Moon and Sun. The ocean-tide loading is the crust displacement in response to ocean tide. The ocean-tide loading causes the crustal deformations not only beneath the world ocean and along coastal regions, but also further inland.

A calculation of the ocean-tide loading utilizes models of the Earth and ocean tide. The ocean tide models describe spatial and temporal variations of the ocean mass load induced by the gravitational attraction of the Moon and Sun. The Earth models describe the elastic (or visco-elastic) response of the Earth to surface load. The most widely used models of the Earth are the Spherical Non-Rotating Elastic Isotropic (SNREI) models such as the Guttenberg-Bullen A model. The SNREI models are commonly used because of a simple definition of their associated Green's functions; Green's functions for these models are defined as an isotropic function of the spherical distance between the observation and loading point. The ocean tide models can formally be subdivided into the global and regional models. The currently available global models have the entire world ocean coverage with a spatial resolution downto 7.5 arc-mingeographical grid. The regional (and local) models are typically compiled with a higher spatial resolution over a specific area based on incorporating more detailed data from tide gauges and bathymetry. Several global ocean tide models are currently available, among them the models of Schwiderski (1980), NAO.99b (Matsumoto et al. 2000), FES94.1, FES95 (Le Provost et

VERSITA 
al. 1998), FES99 (Lefevre et al. 2002), and FES2004 (Letellier 2004), CSR3.0 and CSR4.0 (Eanes 1994), GOT99.2b (Ray 1999), GOT00.2, TPXO.5 through TPXO.7.2 (Egbert and Erofeeva 2002), EOT08a (Savcenko and Bosch 2008), EOT10a (Savcenko and Bosch 2010), AG95.1 (Andersen 1995), and AG06a (Andersen et al. 2006a, b). Majority of these models were compiled using the shallow water hydrodynamic equations. These models also assimilate data from satellite altimetry and tide gauges. An overview of the existing global ocean tide models is given for instance by Agnew (1996) and Penna et al. (2008). A comparison of particular ocean tide models was done by Andersen et al. (1995), Shum et al. (1997), Bos et al. (2002), Lyard et al. (2006), Savcenko and Bosch (2008), and others. All these models were compiled utilizing a spectral harmonic decomposition of the ocean tide into the partial tidal constituents, each with a certain frequency. All calculations are then done for each individual tidal harmonic constituent. This harmonic decomposition allows for a description of the ocean tide series over a certain time period using simple expressions consisting of just a few coefficients which describe the amplitudes and phases of tidal harmonics. An alternative approach was developed by forcing a general circulation model with the full lunisolar tidal potential rather than just single partial tides (cf. Thomas 2001, Weis 2006). This approach allows for an interaction between the partial tides, generation of shallow-water tides, and also for interactions of tidal currents with other ocean currents. However, this approach is numerically very complex and, therefore, rarely used in practice. There are several available software packages for computing the ocean-tide loading prepared by Scherneck et al (2002), Agnew (1997), and others. The comparison of these software packages can be found in Bos and Baker (2005) and Penna et al. (2008).

A high-resolution regional ocean tide model for New Zealand's Exclusive Economic Zone was developed by Walters et al. (2001). It is based on the 2D shallow water equations with all the major nonlinear terms retained. The open boundary conditions were specified from results of the satellite altimetry TOPEX/POSEIDON models FES, ORI, TPXO.2, SR (Shum et al. 1997), and OLE, and then optimized for each tide constituent to obtain the best-fit with the open-coast sea level stations. Goring and Walters (2002) used this model to calculate the vertical deformations at the ocean bottom floor offshore New Zealand caused by the 8 major tidal harmonic constituents $\mathrm{M}_{2}, \mathrm{~S}_{2}, \mathrm{~N}_{2}, \mathrm{~K}_{2}, \mathrm{~K}_{1}, \mathrm{O}_{1}, \mathrm{P}_{1}$, and $\mathrm{Q}_{1}$.

In this study, we analyze the accuracy of the global ocean tide models TPXO7.2, GOT00.2, NAO.99b, FES2004, and EOT10a using the tide-gauge data at 7 stations along the coastline of New Zealand. Since the regional model developed by Walters et al. (2001) is not publically available, we use only the global ocean tide model (which has the best-fit to tide-gauge data) for computing the ocean-tide loading displacements in New Zealand without incorporating detailed regional ocean tide data. The method of computing the ocean-tide loading is briefly reviewed in Section 2. A brief description of the global ocean tide models used for the accuracy assessment in given in Section 3. The assessment of the regional accuracy of global ocean tide models using the tide-gauge data in New Zealand is done in Section 4. The co-tidal charts of the ocean-tide loading (onshore) and the generating ocean tide (offshore) at the study area of New Zealand and surrounding parts of the Tasman Sea and the Pacific Ocean are shown in Section 5. The crustal displacements in New Zealand due to the ocean-tide and atmospheric loading, geodynamic and other phenomena are discussed and compared in Section 6. The summary of results and conclusions are given in Section 7.

\section{Methodology}

A computation of crustal deformations due to ocean tide is based on the method of Farrell (1972). According to his method, the ocean-tide loading displacement $l_{i}$ for a tidal constituent $i$ in the position $(\phi, \lambda)$ is computed as the integral convolution of the ocean tide $h_{i}$ and Green's function $G$ in the following form

$$
I_{i}(\phi, \lambda)=\rho^{w} \int_{\Omega^{\prime} \in \Omega_{\text {ocean }}} G(\psi) h_{i}\left(\phi^{\prime}, \lambda^{\prime}\right) S(\alpha) d \Omega^{\prime},
$$

where $S$ is the trigonometric factor, $\rho^{w}$ is the mean seawater density, $d \Omega^{\prime}=\cos \phi^{\prime} d \phi^{\prime} d \lambda^{\prime}$ is the infinitesimal surface element on the unit sphere, and $\Omega_{\text {ocean }}$ denotes the world ocean surface. The 3D position $(r, \phi, \lambda)$ is defined in the coordinate system of which the origin coincides with the mass centre of the solid Earth as defined in Farrell (1972); $r$ is the radius and $\Omega=(\phi, \lambda)$ denotes the pair of spherical coordinates with the spherical latitude $\phi$ and longitude $\lambda$. The system of polar spherical coordinates $(\alpha, \psi)$ is described by the spherical distance $\psi$ and azimuth $\alpha$.

Green's function $G$ in eqn. (1) defines the elastic respond of the Earth to the oceantide loading. The ocean-tide loading vertical displacements are defined using Green's function $G_{v}$ in the following form (Farrell 1972)

$$
G_{v}(\psi)=\frac{\mathrm{R}}{M} \sum_{n=0}^{\infty} \mathrm{h}_{\mathrm{n}}{ } P_{n}(\cos \psi) .
$$

The Green's function $G_{\mathrm{h}}$ for describing the corresponding horizontal displacements reads (ibid.)

$$
G_{h}(\psi)=\frac{\mathrm{R}}{M} \sum_{n=0}^{\infty} 1_{\mathrm{n}} \frac{\partial P_{n}(\cos \psi)}{\partial \psi}
$$

In eqs. (2) and (3), $\mathrm{R}$ is the Earth mean radius, $\mathrm{M}$ is the total mass of the solid Earth (i.e., excluding masses of the atmosphere and oceans), $h^{\prime}{ }_{n}$ and $l^{\prime}$, are the mass loading Love numbers for a particular model of the Earth, and $\mathrm{P}_{\mathrm{n}}$ are the Legendre polynomials of degree $\mathrm{n}$ for the argument of cosine of the spherical distance $\psi$. The factor $S$ in eq. (1) is defined as: $S(\alpha)=1$ for the vertical displacement, and $S(\alpha)=\cos \alpha$ and $S(\alpha)=-\sin \alpha$ for the meridional and prime-vertical components of the horizontal displacement, respectively. 


\section{Ocean tide models}

In order to select the most suitable global ocean tide model for modeling the ocean-tide loading in New Zealand, the investigation of the regional accuracy of the TPXO7.2, GOT00.2, NAO.99b, FES2004, and EOT10a models is conducted in Section 4.

The TPXO.7.2 model, which best-fits, in a least-squares sense, the Laplace tidal equations and the along-track averaged satellite altimetry data, was developed at the Oregon State University. It is a more recent version of the global solution described in Egbert and Erofeeva (2002). This model was compiled using the TOPEX/POSEIDON and Jason 1 satellite altimetry data (available for the ice-free ocean surface topography between the parallels of \pm 66 arc-deg latitude), in situ tide-gauge records in polar regions and in regions with the complex coastal relief, and assimilating GRACE data.

The FES2004 tidal atlas was developed by Letellier (2004) at the Laboratoire d'Etudes en Géophysique et Océanographie Spatiales (LEGOS) in France with the support of the CNES and the national computational centre IDRIS. FES2004 is the latest release of a series of finite element solutions (FES) tidal atlases, computed from the tidal hydrodynamic equations and data assimilation. The assimilated data are the tidal constants obtained from the tide gauge and satellite (TOPEX/POSEIDON and ERS) sea level analysis. FES2004 solutions have a global coverage, with a with a $7.5 \times 7.5$ arc-min resolution for the released products.

The Goddard Ocean Tide model GOT00.2 was developed at the Goddard Space Flight Center of the National Aeronautics and Space Administration (NASA). GOT00.2 is an update of GOT99.2b (Ray 1999). This model was compiled based on the longwavelength adjustment of FES94.1 using more than 6 years of the TOPEX/POSEIDON altimetry data. GOT99.2b is provided globally on a $30 \times 30$ arc-min geographical grid. Since the ERS12 data were used in the assimilation process, GOT00.2 is different from FES94. 1 in the polar regions outside the 66 arc-deg latitudes, while GOT99.2b is identical with FES94.1.

The NAO.99b short-period ocean tide model was developed at the National Astronomical Observatory in Japan and it is described in detail by Matsumoto et al. (2000). NAO.99b has a global coverage with a $30 \times 30$ arc-min resolution It was compiled based on assimilating tidal solutions from about 5 years of the TOPEX/POSEIDON altimeter data into hydrodynamical model. The coastal tide-gauge data were additionally assimilated for the $5 \times 5$ arc-min regional model NAO.99Jb around Japan.

The ocean tide model EOT10a is the updated version of EOT08a. It is based on a harmonic analysis of multi-mission altimetry data from TOPEX/POSEIDON, Jason-1, 2, ERS2, and ENVISAT collected over nearly 18 years. This model is provided globally with a $7.5 \times 7.5$ arc-min geographical resolution (cf. Savcenko and Bosch 2010)

VERSITA

\section{Accuracy analysis}

To find the global model which is the most suitable for modelling the ocean-tide loading in New Zealand, we compared the ocean tide data from different models with the tide-gauge records. The comparison was done using data over the study period of 1 year (2005) with 1 hour data sampling interval. The ocean tide data from the global models TPX07.2, GOT00.2, NAO.99b, FES2004, and EOT10a were analyzed at the tide-gauge stations in Wellington, Tauranga, Taranaki, Marsden Point, Jackson Bay, Timaru, and Port Charmers. The tide-gauge data were corrected for a secular trend due to the sea level change. The tide-gauge data in Wellington, Tauranga, Marsden Point, Timaru, and Port Charmers are made available by the Land Information New Zealand (LINZ). The data from Taranaki are provided by the Royal New Zealand Navy and data in Jackson Bay by the National Tidal Centre (NTC) in Australia. The examples of the ocean tide data from the TPXO7.2, GOT00.2, NAO99b, FES2004, and EOT10a models at 7 tide-gauge stations in New Zealand over the period between $1^{\text {st }}$ and $20^{\text {th }}$ of January, 2005 (with 1 hour data sampling interval) are shown in Figure 1. As seen, the ocean tide series from all investigated models have similar phase as the phase of tide-gauge series, while the differences in amplitude are typically about 10 to $20 \mathrm{~cm}$ at the stations in Tauranga, Taranaki, Jackson Bay, Timaru, and Port Charmers (cf. Figures $1 b, c, e, f, g)$. On the other hand, the ocean tide series exhibit large discrepancies in phase and amplitude at the tidegauge stations in Wellington and Marsden Point (cf. Figures 1a, d).

Table 1. The average errors of the global ocean tide models TPXO7.2, GOT00.2, NAO.99b, FES2004, and EOT10a at the tide-gauge stations in Wellington, Tauranga, Taranaki, Marsden Point, Jackson Bay, Timaru, and Port Charmers. The average errors were computed from (absolute) differences between the ocean tide and tide-gauge data (over the study period of 2005 with 1 hour data sampling interval) using the arithmetic mean operator.

\begin{tabular}{cccccc}
\hline \multirow{2}{*}{ Tide Gauge } & \multicolumn{5}{c}{ Average Error [cm] } \\
\cline { 2 - 6 } & TPXO7.2 & NAO99b & GOT00.2 & EOT10a & FES2004 \\
\hline \hline Port Chalmers & 17.6 & 17.8 & 16.4 & 17.3 & 17.2 \\
\hline Timaru & 10.9 & 10.9 & 10.7 & 15.2 & 15.4 \\
\hline Jackson Bay & 9.0 & 9.0 & 9.0 & 9.0 & 9.2 \\
\hline Marsden Point & 7.9 & 13.7 & 10.9 & 54.2 & 11.2 \\
\hline Taranaki & 9.2 & 9.0 & 9.2 & 10.5 & 11.9 \\
\hline Tauranga & 11.1 & 11.0 & 10.9 & 11.2 & 11.1 \\
\hline Wellington & 8.7 & 11.3 & 25.7 & 9.7 & 9.8 \\
\hline
\end{tabular}

The average errors of the ocean tide models over the whole study period of 1 year (2005) are summarized in Table 1. The TPXO7.2 model has the best-fit to tide-gauge data and thus provides the most accurate solution for the coastline of New Zealand. The bestfit of TPX07.2 with the tide-gauge data in terms of the average error is $7.9 \mathrm{~cm}$ in Marsden Point located at the upper North Island. 


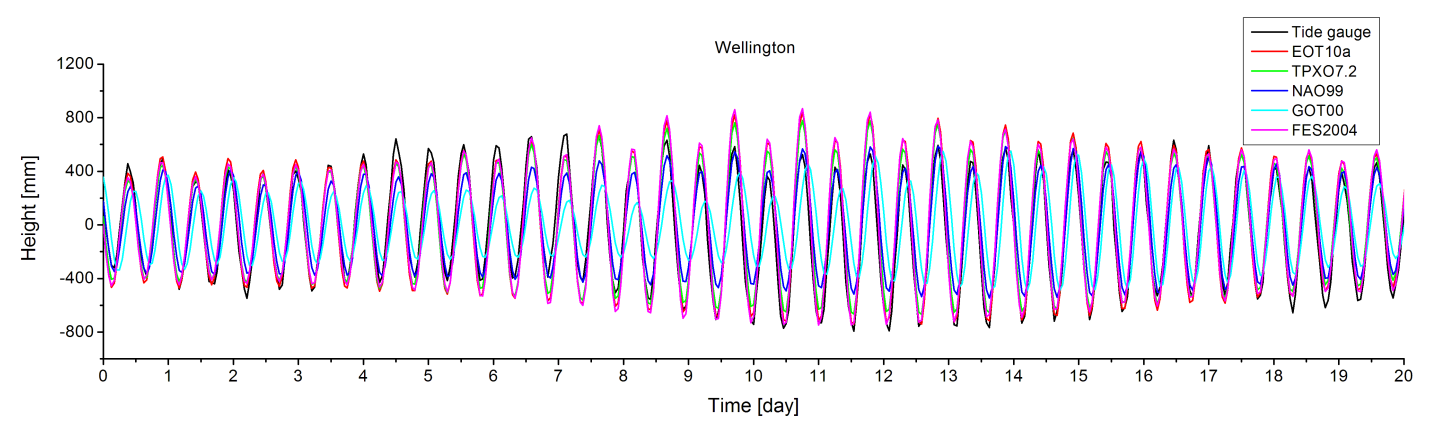

a)

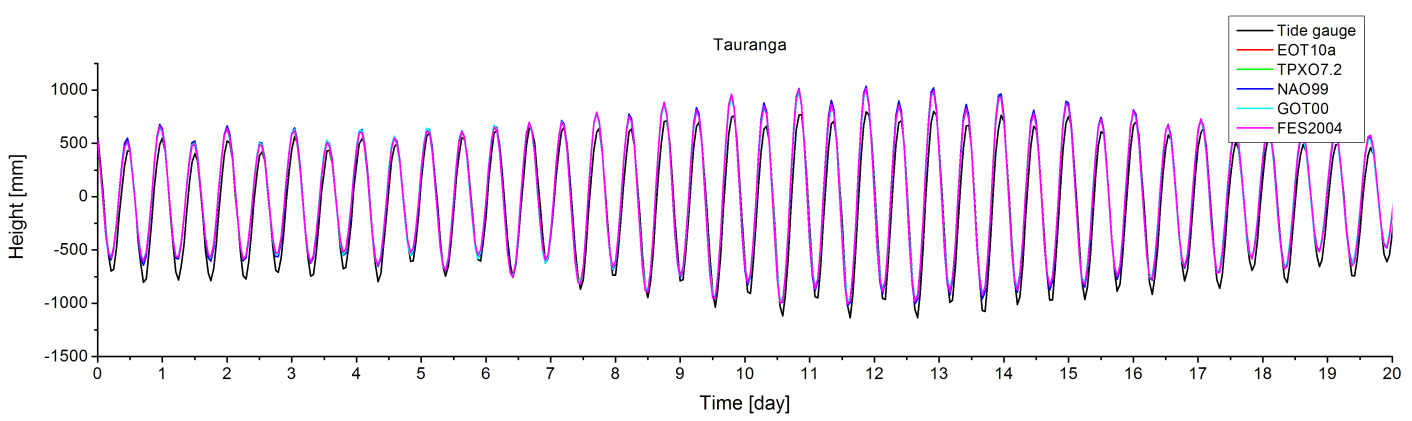

b)

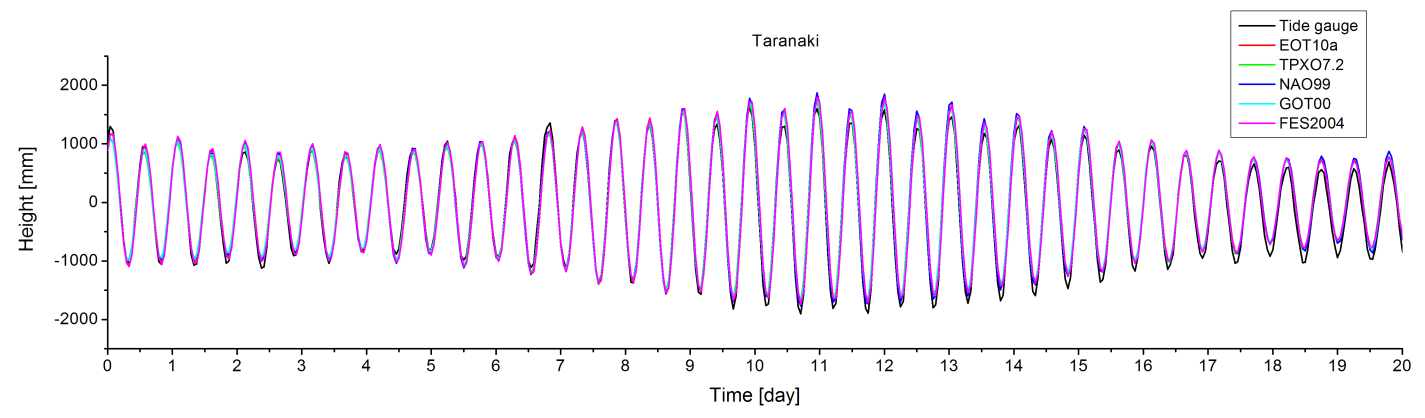

c)

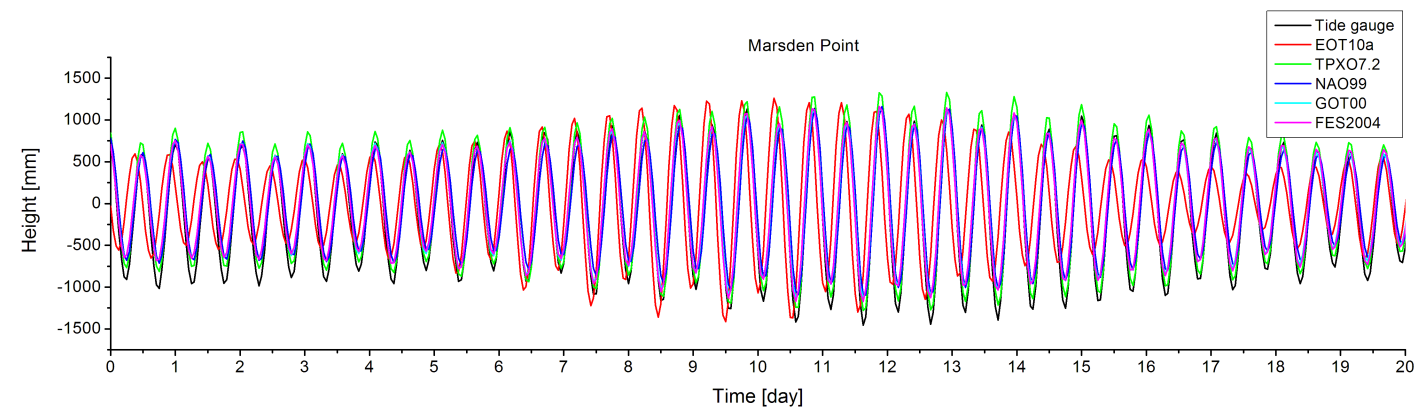

d) 


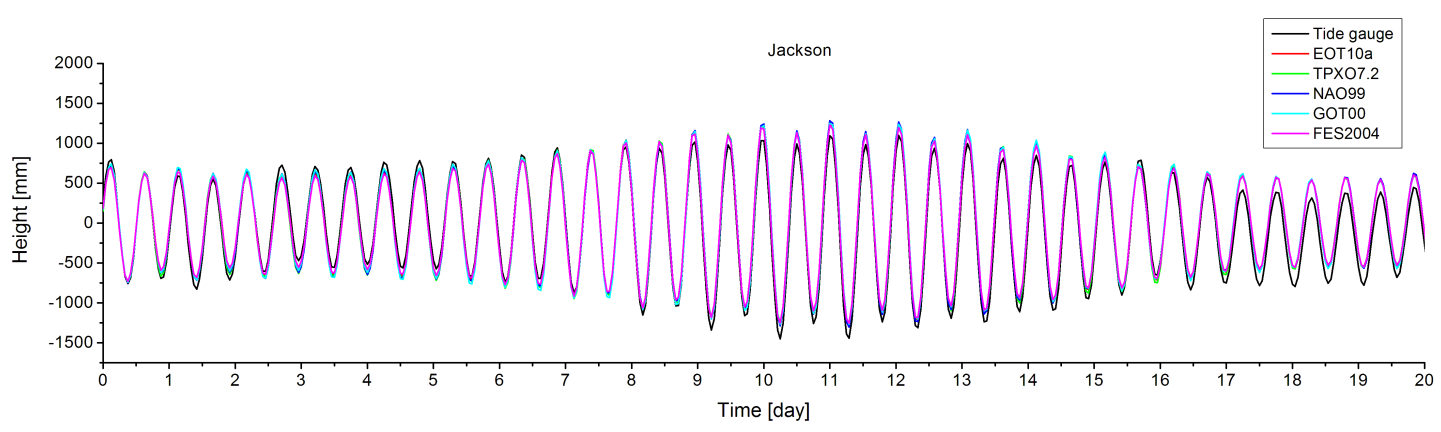

e)

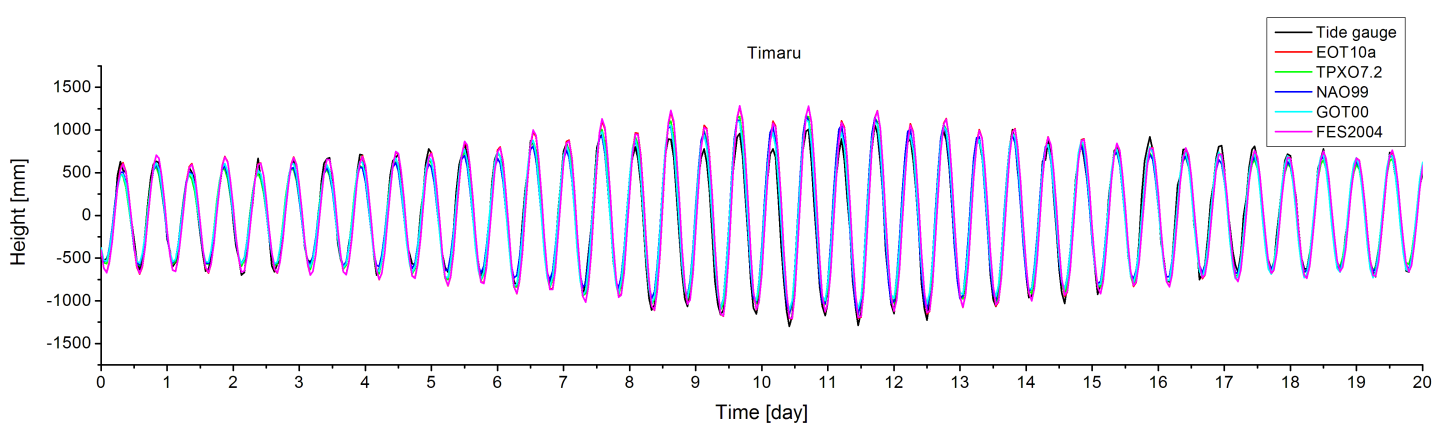

f)

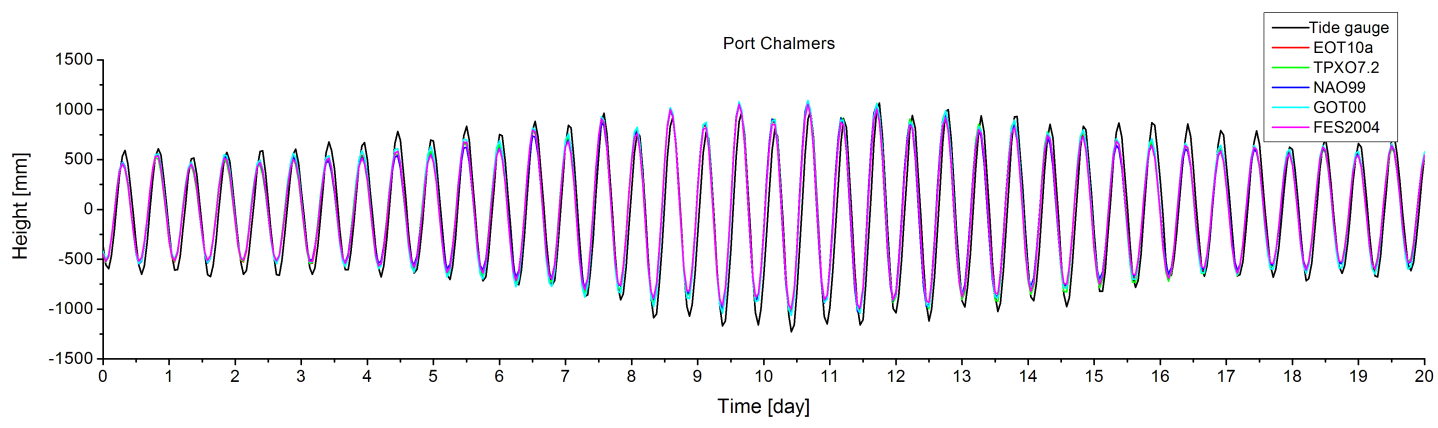

g)

Figure 1. The comparison of the TPXO7.2, GOT00.2, NAO.99b, FES2004, and EOT10a ocean tide series with the tide-gauge data in: (a) Wellington, (b) Tauranga, (c) Taranaki, (d) Marsden Point, (e) Jackson Bay, (f) Timaru, and (g) Port Charmers between $1^{\text {st }}$ and $20^{\text {th }}$ of January, 2005 (1 hour data sampling interval).

The largest differences between TPXO7.2 and tide-gauge data are found in Port Charmers situated at the south-east part of the South Island, where average error is $17.6 \mathrm{~cm}$. These discrepancies are mainly due to the different phases of the ocean tide series and tide-gauge data, while the differences in amplitude are typically at the level of only a few centimetres. For comparison, the average error of the EOT10a model in Marsden Point is $54.2 \mathrm{~cm}$, and the corresponding average error of the GOT00.2 model in Wellington is $25.7 \mathrm{~cm}$. The presence of large errors of EOT10a (in Marsden Point) and GOT00.2 (in Wellington) are also evident from Figure 2, where we shown the accuracy of the GOT00.2, NAO99b, FES2004, and EOT10a models relative to TPXO7.2. 


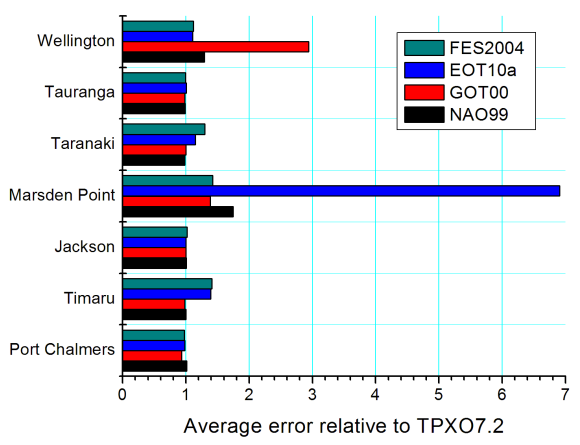

Figure 2. The accuracy of GOT00.2, NAO.99b, FES2004, and EOT10a relative to the TPXO7.2 ocean tide model at 7 tide-gauge stations (Wellington, Tauranga, Taranaki, Marsden Point, Jackson Bay, Timaru, and Port Charmers). The study period of 1 year (2005) with 1 hour data sampling interval.

\section{Results}

The global inverse ocean tide model TPX0.7.2 with a spatial resolution of $15 \times 15$ arc-min was used to compute the oceantide loading in New Zealand. The computation of the ocean-tide loading was realized on a $5 \times 5$ arc-min geographical grid according to eq. (1). In addition, the corresponding ocean tide was computed on a $5 \times 5$ arc-min geographical grid offshore New Zealand at the study area bounded by the parallels of 34 and 48 arc-deg southern latitude and the meridians of 166 and 179 arc-deg eastern longitude. Green's functions $G_{v}$ and $G_{\mathrm{h}}$ for the ocean-tide loading vertical and horizontal displacements were computed according to eqs. (2) and (3) using the mass loading Love numbers $h^{\prime}{ }_{n}$ and $\mathrm{l}_{\mathrm{n}}$ taken from the Gutenberg-Bullen A standard model of the Earth (Farrell 1972). This model assumes that the Earth responds elastically under loadings at tidal frequencies.

The ocean-tide loading was calculated for the semi-diurnal and diurnal tidal harmonic constituents $\mathrm{M}_{2}, \mathrm{~S}_{2}, \mathrm{~N}_{2}, \mathrm{~K}_{2}, \mathrm{~K}_{1}, \mathrm{O}_{1}, \mathrm{P}_{1}$, and $\mathrm{Q}_{1}$, the long-period tidal components $M_{f}$ and $M_{m}$, and for the shallowwater components $\mathrm{M}_{4}, \mathrm{MS}_{4}$, and $\mathrm{MN}_{4}$ The amplitudes of the oceantide loading constituents are summarized in Table 2 . The co-tidal charts of the ocean-tide loading and the corresponding generating ocean tide are shown in Figures 3-10. The amplitudes are given in $\mathrm{mm}$ and phases in arc-deg. The phase lag is relative to Greenwich, with lags positive. The ocean-tide loading displacements are defined positive in the upward, north and east directions. As acquired by Walters et al. (2001), the spatial distribution of pairs of tidal constituents are similar, forming five groups: $M_{2}$ and $N_{2}$; $\mathrm{S}_{2}$ and $\mathrm{K}_{2} ; \mathrm{K}_{1}$ and $\mathrm{P}_{1} ; \mathrm{O}_{1}$ and $\mathrm{Q}_{1} ; \mathrm{M}_{f}$ and $\mathrm{M}_{m}$. Therefore, the co-tidal charts in Figures 3-10 are provided only for the principal tidal harmonic constituents $\mathrm{M}_{2}, \mathrm{~S}_{2}, \mathrm{~K}_{1}, \mathrm{O}_{1}$, and $\mathrm{M}_{f}$, and for all three investigated shallow-water components $\mathrm{M}_{4}, \mathrm{MS}_{4}$, and $\mathrm{MN}_{4}$. The individual ocean-tide loading harmonic constituents are discussed in the next paragraphs of this section. A behavior of the tidal generating components $\mathrm{M}_{2}, \mathrm{~S}_{2}, \mathrm{~N}_{2}, \mathrm{~K}_{2}, \mathrm{~K}_{1}, \mathrm{O}_{1}, \mathrm{P}_{1}$, and $\mathrm{Q}_{1}$ around New Zealand is described in detail by Walters et al. (2001).

$\mathrm{M}_{2}$ and $\mathrm{N}_{2}$ : The maxima of vertical displacements are found in the Northland and the East Cape, while the minima in the Canterbury region. Although the ocean tide amplitudes are large along the east coast of Canterbury (Figure 3a), the vertical displacements in this region are almost negligible (Figure $3 b$ ). This phenomenon is attributed to the presence of an amphidromic point (located near Timaru for $M_{2}$, and to the north-west from Christchurch for $\mathrm{N}_{2}$ ). The load contributions from different sides around this point are out of phase, so they almost cancel each other. The vertical displacement wave propagates around the amphidrome in a counter-clockwise direction similar to the wave of generating ocean tide. The spatial distribution of vertical displacements in New Zealand can be thought as a field of differences between the amplitudes of surrounding tides taken from the opposite sides of the corresponding amphidromic point. The meridional horizontal displacements reach their maxima near Nelson, and their minima on the coast of Hawke's Bay (Figure 3c). Their waves propagate along the curve that passes through the North Cape, Wellington, and then through the west coast region of the South Island. The propagation of these waves is clockwise, which is opposite to the direction of the wave of vertical displacements. The maxima of prime-vertical horizontal displacements are found along the coast between New Plymouth and Auckland, at the north of Westport, and around Greymouth (Figure 3d). The minima of meridional horizontal displacements are on the East and West Cape. The wave of meridional horizontal displacements crosses the North Island from Waikato through Hawke's Bay, and in the South Island it propagates westward from Otago to the Fiordland.

$S_{2}$ and $K_{2}$ : The generating ocean tide constituents $S_{2}$ and $K_{2}$ also rotate in a counter-clockwise direction around New Zealand (Figure 4a), but their spatial distribution is different from the constituents $M_{2}$ and $N_{2}$. The presence of additional amphidromic points further east of New Zealand makes the amplitudes of these ocean-tide constituents on the eastern coast very small. The vertical ocean-tide loading wave propagates from the north to south and then bends eastward in the South Island in the same way as the generating tide on the west coast of both islands (Figure 4b). The vertical displacements do not have an amphidrome inland, so their amplitude distribution is similar to that of the generating tidal components. The maxima of vertical displacements are located in the Northland, Cape Egmont, and Cape Farewell. The maxima of meridional horizontal displacements are located near Nelson and to the north of Westport (Figure 4c). The maxima of prime-vertical horizontal displacements are distributed along the coast between New Plymouth and Auckland (Figure 4d). The minima of vertical displacements are along the east coast of both islands. The minima of meridional horizontal displacements are along Hawke's Bay and near Gisborne. The prime-vertical horizontal displacements have minima on the East Cape and in Dunedin. The wave of meridional 

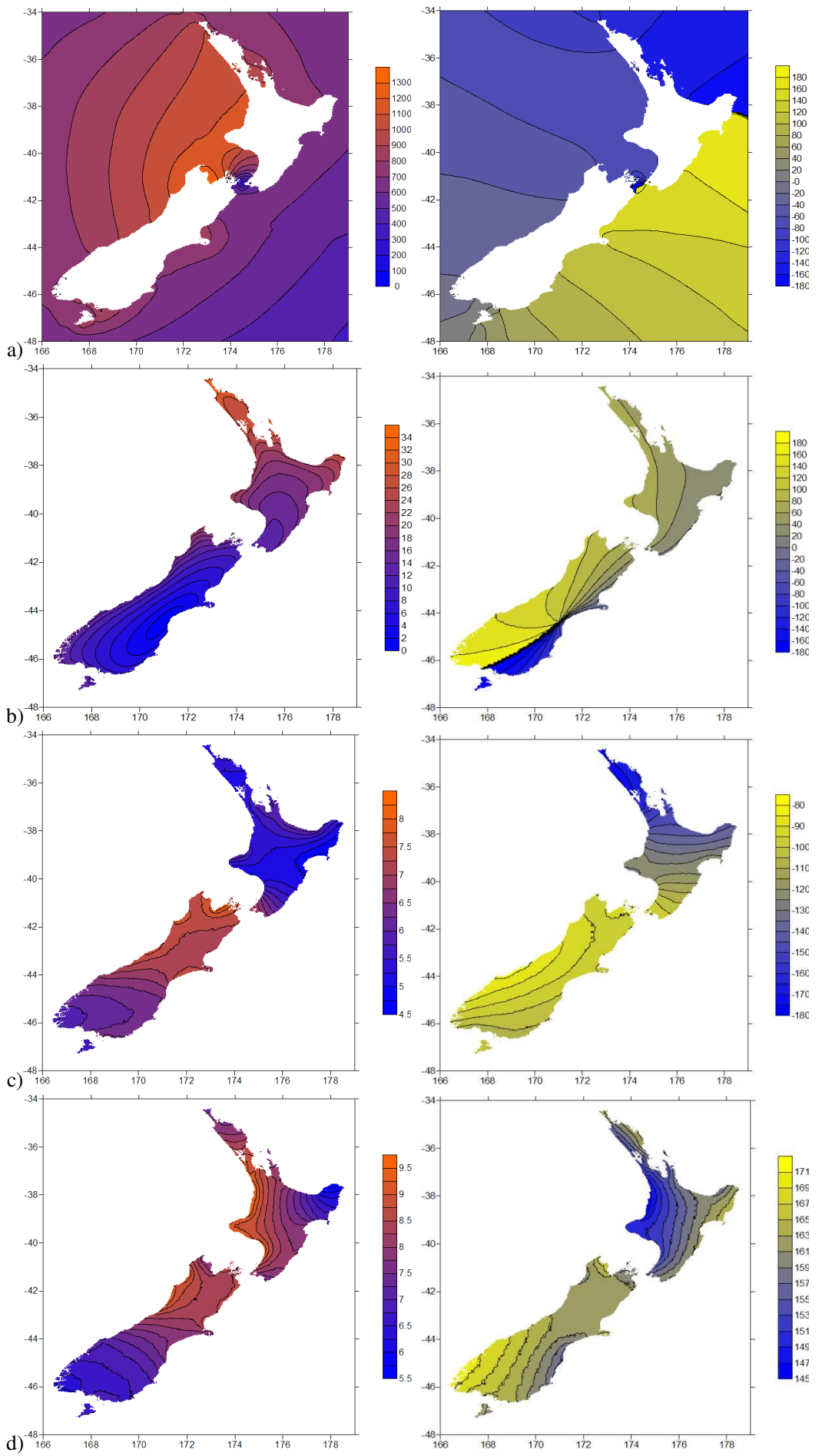

Figure 3. The amplitudes (left panels) and phases (right panels) of the principal lunar semi-diurnal harmonic tidal constituent $M_{2}$ : (a) the ocean tide, (b) the ocean-tide loading vertical displacement, (c) the meridional component of the ocean-tide loading horizontal displacement, and (d) the prime-vertical component of the ocean-tide loading horizontal displacement. (Units: amplitudes in mm, phases in arc-deg). 
Table 2. The ocean-tide loading amplitudes in New Zealand computed for the semi-diurnal and diurnal tidal harmonic constituents $M_{2}, S_{2}, N_{2}, K_{2}$, $\mathrm{K}_{1}, \mathrm{O}_{1}, \mathrm{P}_{1}$, and $\mathrm{Q}_{1}$, the long-period tidal components $\mathrm{M}_{f}$ and $\mathrm{M}_{m}$, and for the shallow-water components $\mathrm{M}_{4}, \mathrm{MS}_{4}$, and $\mathrm{MN}_{4}$.

\begin{tabular}{lccccc}
\hline & \multirow{2}{*}{ Ocean-tide loading harmonic constituents } & \multirow{2}{*}{ Period } & \multicolumn{3}{c}{ Amplitude [mm] } \\
\cline { 5 - 7 } & & & Vertical & North & East \\
\hline \hline $\mathrm{M}_{2}$ & Principal lunar semi-diurnal & $12.4206 \mathrm{~h}$ & $0.16-32.6$ & $4.68-8.13$ & $5.64-9.46$ \\
\hline $\mathrm{S}_{2}$ & Principal solar semi-diurnal & $12.0000 \mathrm{~h}$ & $2.23-7.90$ & $0.98-1.82$ & $0.55-1.45$ \\
\hline $\mathrm{N}_{2}$ & Larger lunar elliptic semi-diurnal & $12.6583 \mathrm{~h}$ & $0.02-5.8$ & $1.03-1.59$ & $1.31-2.10$ \\
\hline $\mathrm{K}_{2}$ & Luni-solar declinational semi-diurnal & $11.9672 \mathrm{~h}$ & $0.83-2.27$ & $0.30-0.52$ & $0.12-0.39$ \\
\hline $\mathrm{K}_{1}$ & Luni-solar declinational diurnal & $23.9345 \mathrm{~h}$ & $2.06-5.56$ & $1.38-1.80$ & $0.62-0.88$ \\
\hline $\mathrm{O}_{1}$ & Principal lunar declinational diurnal & $25.8193 \mathrm{~h}$ & $0.36-3.85$ & $1.11-1.35$ & $0.59-0.83$ \\
\hline $\mathrm{P}_{1}$ & Principal solar declinational diurnal & $24.0659 \mathrm{~h}$ & $0.67-1.58$ & $0.43-0.56$ & $0.18-0.27$ \\
\hline $\mathrm{Q}_{1}$ & Lunar elliptic diurnal & $26.8684 \mathrm{~h}$ & $0.21-1.08$ & $0.25-0.30$ & $0.14-0.20$ \\
\hline $\mathrm{M}_{f}$ & Lunar declinational fortnightly & $13.6608 \mathrm{~d}$ & $0.22-1.08$ & $0.15-0.20$ & $0.00-0.06$ \\
\hline $\mathrm{M}_{m}$ & Lunar elliptic monthly & $27.5545 \mathrm{~d}$ & $0.07-0.56$ & $0.09-0.11$ & $0.00-0.02$ \\
\hline \multicolumn{7}{c}{ Shallow-water ocean-tide loading components } & & & & \\
\hline $\mathrm{M}_{4}$ & $2 \times \mathrm{M}_{2}$ & $6.2103 \mathrm{~h}$ & $0.00-0.21$ & $0.00-0.05$ & $0.00-0.07$ \\
\hline $\mathrm{MS}_{4}$ & $\mathrm{M}_{2}+\mathrm{S}_{2}$ & $6.1033 \mathrm{~h}$ & $0.00-0.18$ & $0.00-0.04$ & $0.00-0.04$ \\
\hline $\mathrm{MN}_{4}$ & $\mathrm{M}_{2}+\mathrm{N}_{2}$ & $6.2692 \mathrm{~h}$ & $0.00-0.12$ & $0.01-0.04$ & $0.01-0.03$ \\
\hline \multicolumn{7}{c}{} & & & & &
\end{tabular}

horizontal displacements for $\mathrm{S}_{2}$ and $\mathrm{K}_{2}$ components propagates in the same way as the corresponding $M_{2}$ wave. The wave of prime-vertical horizontal displacements crosses the North Island from the west to east, and the South Island from the north-east to south-west.

$\mathrm{K}_{1}$ and $\mathrm{P}_{1}$ : The maxima of vertical displacements are in the Northland (Figure 5b), while the maxima of horizontal displacements are located in the Fiordland (Figures 5c, d). The minima of vertical displacements are in Canterbury and Wellington. The minima of meridional horizontal displacements are between Gisborne and the East Cape. The minima of prime-vertical horizontal displacements are between Banks Peninsula and Kaikoura. The vertical displacement wave propagates from the south to north, and the horizontal displacement wave from the south-west to north-east along the South Island, and then deflects towards the north-west on the North Island.

$\mathrm{O}_{1}$ and $\mathrm{Q}_{1}$ : The maxima of vertical displacements are in the West Cape and in the south part of the Steward Island (Figure 6b). The maxima of meridional horizontal displacements are on the southern coast of the South Island and in the Steward Island (Figure 6c), while the maxima of prime-vertical horizontal displacements are in the Fiordland (Figure 6d). The minima of all horizontal and vertical displacements are found in the East Cape. The vertical displacements have amphidromic points at the north-east of the East Cape; the loading waves propagate around those points in clockwise direction. The phases of meridional horizontal displacements have a pattern similar to the corresponding semi-diurnal waves; however, they propagate in opposite direction (counterclockwise). The prime-vertical horizontal displacements propagate from the south-west to north-east.

$\mathrm{M}_{f}$ and $\mathrm{M}_{m}$ : The generating ocean-tide amplitudes increase grad- ually from the north to south, while the change of their phase lag is very small (Figure 7a). The resulting vertical displacements have a similar pattern (Figure 7b). They gradually increase from the Northland southward, reaching a maximum in the south coast of the Steward Island. Their phase lag variation is small and repeats the phase variation of the generating tide (increasing from the south-west to north-east in the case of $M_{f}$, and from the northwest to south-east in the case of $M_{m}$ ). The meridional horizontal displacements have the maxima along the coast between Dunedin and Invercargill, and along the coast between Wellington and Gisborne (Figure 7c). The corresponding minima are around Jackson Bay. The maxima of prime-vertical horizontal displacements are along the coast between Timaru and Dunedin (Figure 7d). The corresponding minima of $M_{f}$ component are on the West Coast and on the Cape Egmont, while the minima of $\mathrm{M}_{m}$ component are along the strip that goes from the north-east to south-west through the centres of both islands. The wave of meridional horizontal displacements propagates in a trajectory similar to the corresponding semi-diurnal wave with some irregularities at the North Island. The prime-vertical horizontal displacements propagate from the north-west to south-east in the case of $M_{f}$, and in the opposite direction in the case of $M_{m}$.

The amplitudes of shallow-water generating tide components are small everywhere around New Zealand except in Cook Straight and Hauraki Gulf (Figures 8a, 9a, 10a). The MS 4 ocean-tide component slightly increases near the coast of Canterbury (Figure 9a).

$\mathrm{M}_{4}$ : The maxima of vertical deformations are around Auckland, and their minima are found in the Manawatu-Wanganui region of the North Island, in the Marlborough region of the South Island, and also between Queenstown lakes and along the west coast of the South Island (Figure 8b). The maxima of meridional hori- 



Figure 4. The amplitudes (left panels) and phases (right panels) of the principal solar semi-diurnal harmonic tidal constituent $\mathrm{S}_{2}$ : (a) the ocean tide, (b) the ocean-tide loading vertical displacement, (c) the meridional component of the ocean-tide loading horizontal displacement, and (d) the prime-vertical component of the ocean-tide loading horizontal displacement. (Units: amplitudes in mm, phases in arc-deg). 

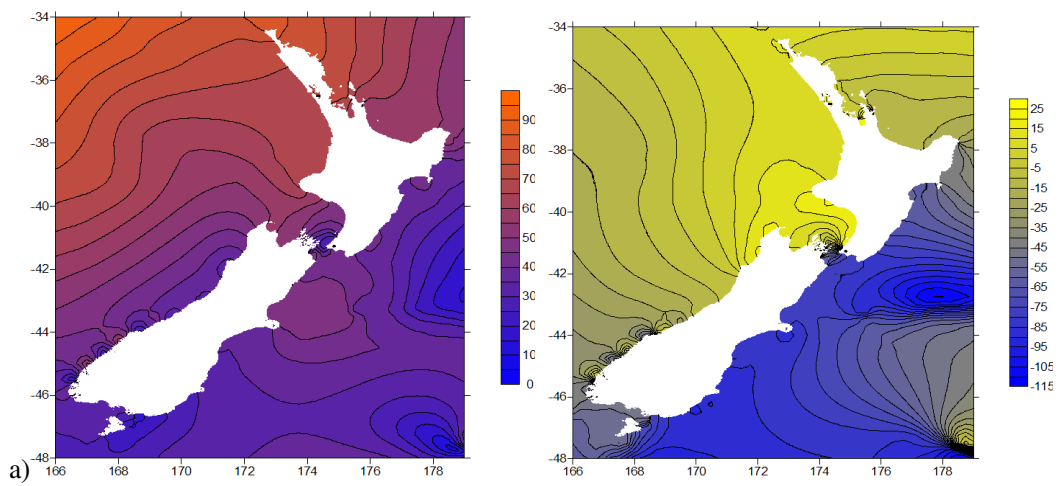

b)


Figure 5. The amplitudes (left panels) and phases (right panels) of the luni-solar declinational diurnal harmonic tidal constituent $\mathrm{K}_{1}$ : (a) the ocean tide, (b) the ocean-tide loading vertical displacement, (c) the meridional component of the ocean-tide loading horizontal displacement, and (d) the prime-vertical component of the ocean-tide loading horizontal displacement. (Units: amplitudes in mm, phases in arc-deg). 

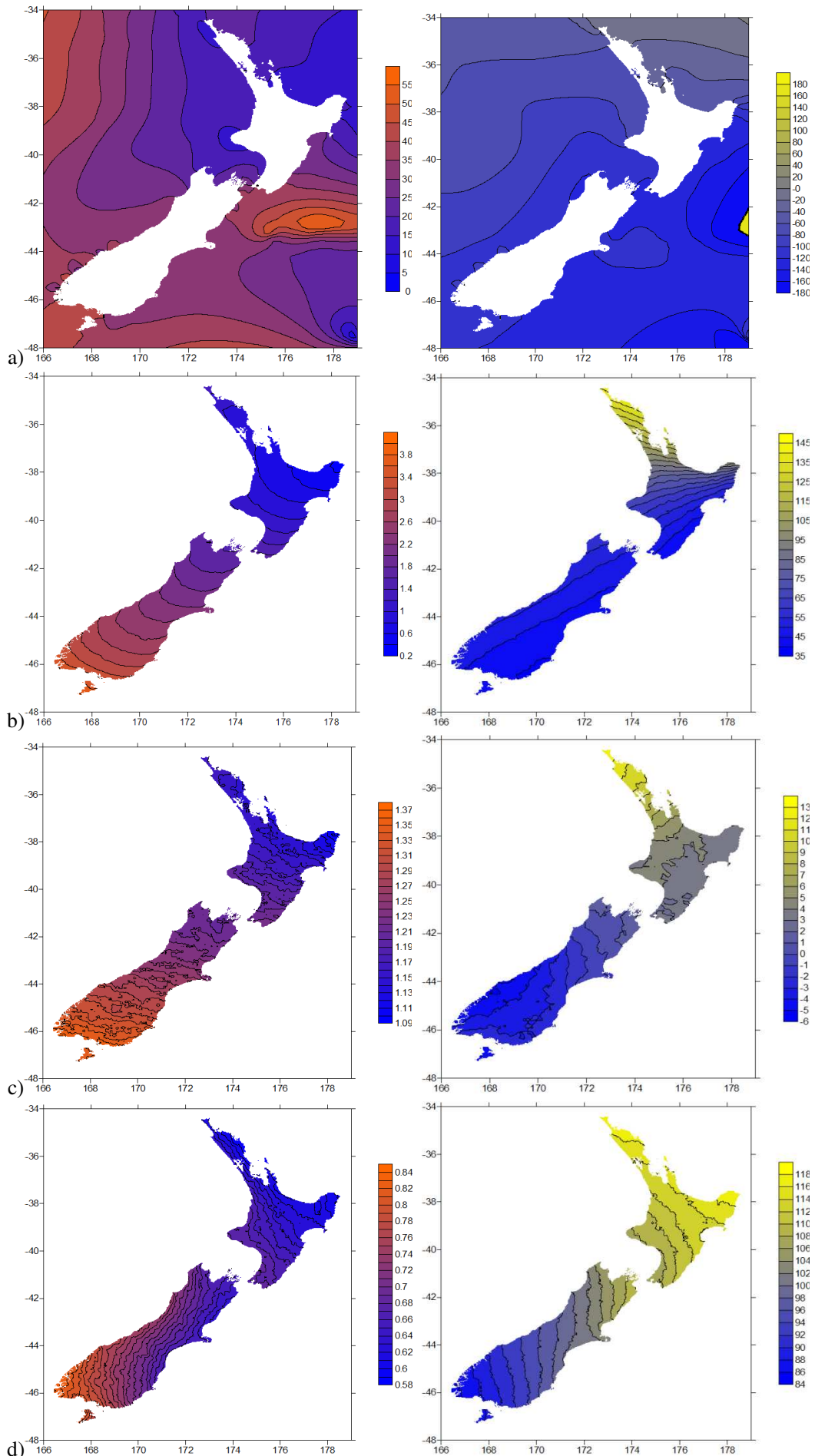

Figure 6. The amplitudes (left panels) and phases (right panels) of the principal lunar declinational diurnal harmonic tidal constituent $\mathrm{O}_{1}:(\mathbf{a})$ the ocean tide, (b) the ocean-tide loading vertical displacement, (c) the meridional component of the ocean-tide loading horizontal displacement, and (d) the prime-vertical component of the ocean-tide loading horizontal displacement. (Units: amplitudes in mm, phases in arc-deg). 

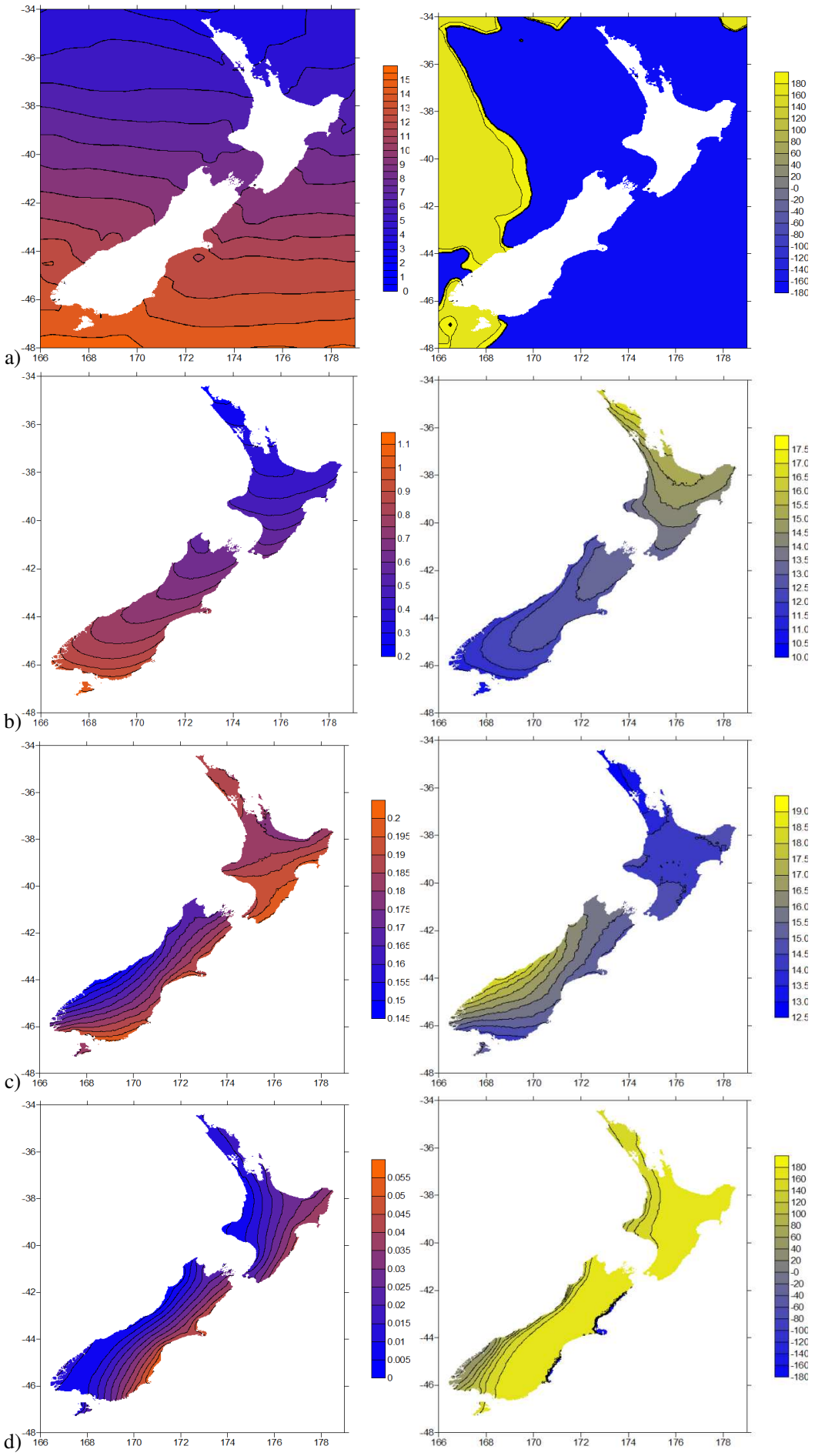

Figure 7. The amplitudes (left panels) and phases (right panels) of the and lunar elliptic monthly harmonic tidal constituent $\mathrm{M}_{f}$ : (a) the ocean tide, (b) the ocean-tide loading vertical displacement, (c) the meridional component of the ocean-tide loading horizontal displacement, and (d) the prime-vertical component of the ocean-tide loading horizontal displacement. (Units: amplitudes in mm, phases in arc-deg). 



Figure 8. The amplitudes (left panels) and phases (right panels) of the nonlinear shallow-water tidal component $\mathrm{M}_{4}$ : (a) the ocean tide, (b) the ocean-tide loading vertical displacement, (c) the meridional component of the ocean-tide loading horizontal displacement, and (d) the prime-vertical component of the ocean-tide loading horizontal displacement. (Units: amplitudes in $\mathrm{mm}$, phases in arc-deg). 



Figure 9. The amplitudes (left panels) and phases (right panels) of the nonlinear shallow-water tidal component $\mathrm{MS}_{4}$ : (a) the ocean tide, (b) the ocean-tide loading vertical displacement, (c) the meridional component of the ocean-tide loading horizontal displacement, and (d) the prime-vertical component of the ocean-tide loading horizontal displacement. (Units: amplitudes in mm, phases in arc-deg). 
zontal displacements are on the Cape Egmont and their minima are near Hurunui in the Canterbury region (Figure 8c). The maxima of prime-vertical deformations are along the coast between New Plymouth and Auckland, and near Thames, and their minima are along the strip across the South Island that passes between the east and west coasts through Ashburton and Whataroa (Figure $8 \mathrm{~d}$ ). The wave of vertical displacements propagates from the West Cape in the north-east direction through the South Island, and then rotates counter-clockwise around an amphidromic point located in the middle of the North Island. The wave of meridional horizontal displacements propagates through the North Island from the Northland to the south-east, and then bends westward to Wellington. On the South Island, it propagates from the north-west to south-east. This behavior is influenced by three amphidromic points around New Zealand. The prime-vertical horizontal displacements predominantly propagate from the south-west to north-east with the presence of some small irregularities.

$\mathrm{MS}_{4}$ : The maxima of vertical displacements are around Dunedin and on the Banks Peninsula, and their minima are along the strip from the North Cape to the south through Nelson (Figure 9b). The maxima of meridional horizontal displacements are along the coast between Ashburton and Little River, and their minima are on the Cape Farewell (Figure 9c). The prime-vertical horizontal displacements have maxima close to Auckland and at the Steward Island (Figure 9d). Their minima are in the Grey district in the West Coast region of the South Island. The wave of vertical displacements propagates from the south to north. The meridional horizontal displacements propagate from the West Cape in the north-east direction along the South Island and then turn towards the Cape Egmont. The prime-vertical horizontal displacements rotate counter-clockwise around an amphidromic point near Greymouth.

$\mathrm{MN}_{4}$ : The maxima of vertical displacements are found in the same places as the corresponding maxima of $\mathrm{M}_{4}$ vertical displacements. The minima of vertical displacements are in the Fiordland, Marlborough, and to the north-east of Wellington (Figure 10b). The minima of meridional horizontal displacements are in Auckland and Marlborough (Figure 10c). The minima of prime-vertical horizontal displacements are around Greymouth (Figure 10d). The wave of vertical displacements rotates counter-clockwise around the amphidromic point in Manawatu-Wanganui. The wave of meridional horizontal displacements in the North Island converges from all directions to the point close to Cape Egmont. In the South Island, it propagates from the south-east to north-west. The wave of primevertical horizontal displacements propagates from the south-west to north-east.

\section{Discussion}

The location of New Zealand at mid-latitudes means that there are large tidal displacements (e.g., Ray and Sanchez 1989). The amplitude of the principal lunar semi-diurnal Earth tide $M_{2}$ varies

VERSITA from $5.9 \mathrm{~cm}$ in the south to $10.4 \mathrm{~cm}$ in the north of New Zealand (cf. Goring and Walters 2002). They also demonstrated that the diurnal amplitudes of the Earth tide are larger than $90 \%$ of the global maxima for the whole country; for example the amplitudes of the luni-solar declinational diurnal Earth tide $\mathrm{K}_{1}$ and the principal lunar declinational diurnal Earth tide $\mathrm{O}_{1}$ reach $6.7 \mathrm{~cm}$ and $5.5 \mathrm{~cm}$, respectively. Theoretical studies by Rabbel and Zschau (1985), Rabbel and Schuh (1986), vanDam and Wahr (1987), and Manabe et al. (1991) ascertained that the atmospheric loading displacements up to about $25 \mathrm{~mm}$ are possible at mid-latitudes for the vertical component and to about $3 \mathrm{~mm}$ for the horizontal components. These effects are smaller at mid-latitude sites and at locations within $500 \mathrm{~km}$ of the coastal areas due to the inverted barometer response of the ocean. Gladkikh and Tenzer (2010) investigated the crustal displacements in New Zealand due to the atmospheric pressure loading using meteorological data over the study period from 1948 to 2009. They demonstrated that the maxima of vertical motions reached $7.7 \mathrm{~mm}$ over that period. The corresponding horizontal motions reached maxima to about $1.8 \mathrm{~mm}$. As seen in Table 2, the vertical and horizontal ocean-tide loading displacements in New Zealand reach maxima up to $5.6 \mathrm{~cm}$ and $2.1 \mathrm{~cm}$, respectively. The maxima of the ocean-tide loading displacements in New Zealand are thus typically an order of magnitude larger than the maxima of the atmospheric loading displacements. On the other hand, the Earth tide displacements are much larger than the ocean-tide loading displacements. There is also evident that the geographical distributions of the ocean-tide and atmospheric loading exhibit a very complex pattern depending on numerous factors (such as the geometry of coastline), whereas the Earth tide has only a zonal geographical distribution.

In addition to the Earth tide and the ocean-tide and atmospheric loading, there are other geodynamic and climatic phenomena which have to be taken into consideration in precise geodetic and geosciences applications. In particular, we refer to tectonic, volcanic, postglacial isostatic, and pole motion crustal displacements. The location of New Zealand directly over the boundary between the Pacific and Australian lithospheric plates results in large tectonic motions present throughout the country. To the north of New Zealand and beneath the eastern North Island, the Pacific plate moves under the Australian plate in a process known as subduction. Beneath the south-west part of the South Island, the Australian plate is forced below the Pacific plate, while in the central South Island the tectonic plates are colliding as oblique strike slip. In this region the tectonic plate margin is marked by the Alpine Fault. The horizontal tectonic rates in New Zealand reach maxima up to 3-5 cm/year (cf. Bourne et al. 1998, Beavan et al. 1999, 2002, 2007, Beavan and Haines 2001, Wallace et al. 2004, 2007). Except for the Southern Alps (central South Island) and the Taupo volcanic zone (North Island), the currently available information indicates that the vertical motions are an order of magnitude smaller than the horizontal motions. The systematic tectonic subsidence to about $10 \mathrm{~mm} /$ year is detected in the central 

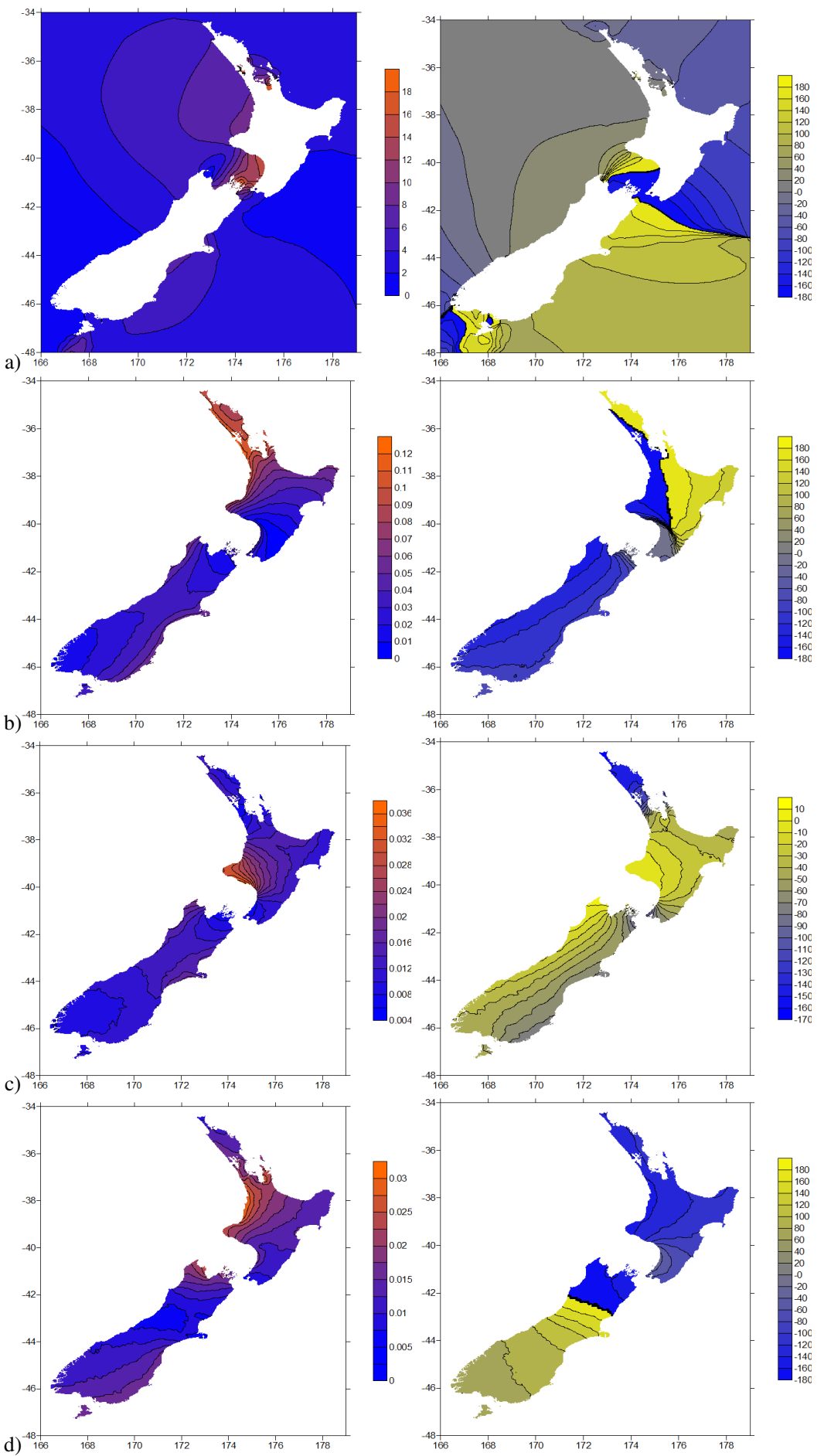

Figure 10. The amplitudes (left panels) and phases (right panels) of the nonlinear shallow-water tidal component $\mathrm{MN}_{4}$ : (a) the ocean tide, (b) the ocean-tide loading vertical displacement, (c) the meridional component of the ocean-tide loading horizontal displacement, and (d) the prime-vertical component of the ocean-tide loading horizontal displacement. (Units: amplitudes in mm, phases in arc-deg). 
Table 3. The maximum amplitudes $(\mathrm{mm})$ and rates ( $\mathrm{mm} / \mathrm{year}$ ) of the periodic and secular crustal deformations in New Zealand due to various climatic and geodynamic factors.

\begin{tabular}{cccc}
\hline \multirow{2}{*}{ Climatic and Geodynamic Factors } & \multicolumn{2}{c}{ Crustal Deformations } \\
\cline { 2 - 4 } & Vertical & Horizontal \\
\hline \hline \multirow{3}{*}{ Periodic } & Ecean-Tide Loading & $350 \mathrm{~mm}$ & $80 \mathrm{~mm}$ \\
\cline { 2 - 4 } & Atmospheric Loading & $7.7 \mathrm{~mm}$ & $21 \mathrm{~mm}$ \\
\cline { 2 - 4 } & Pole Motion & $12.2 \mathrm{~mm}$ & $1.8 \mathrm{~mm}$ \\
\hline \multirow{3}{*}{ Secular } & Tectonic & $\sim 10 \mathrm{~mm} /$ year & $\sim 30-50 \mathrm{~mm} /$ year \\
\cline { 2 - 4 } & Volcanic & $\sim 5 \mathrm{~mm} /$ year & $?$ \\
\cline { 2 - 4 } & Postglacial Isostatic Adjustment & $0.45 \mathrm{~mm} /$ year & - \\
\cline { 2 - 4 } & Pole Motion & $<0.1 \mathrm{~mm} /$ year & $<0.1 \mathrm{~mm} /$ year \\
\hline
\end{tabular}

and lower regions of the North Island (Tenzer et al. 2009). The tectonic uplift along the Southern Alps (South Island) is estimated to be up to about $5 \mathrm{~mm} /$ year (Beavan et al. 2004, 2010). The local uplift to about $5 \mathrm{~mm}$ /year in the central volcanic zone of the North Island is more likely atributed to volcanic processes in this region. The investgation of the glacial isostatic adjustment in New Zealand using global data from the ICE-5G (VM2 L90) model version 1.2b (Peltier 2004) revealed that it is everywhere positive and reaches the maxima up to $0.45 \mathrm{~mm} /$ year in the central North Island. The variations in the angular velocity of the Earth rotation and in the actual position of the Earth rotation axis perturb the centrifugal force and consequently deform the surface of the Earth. Since the relative variations in the Earth rotation rate do not exceed $10^{-8}$ while the variations in the pole coordinates are about $1 \times 10^{-6}$ to $4 \times 10^{-6}$ radians (cf. Petrov 1998), changes of the centrifugal force are mainly due to variations of the Earth rotation axis (pole motion). The change in the centrifugal potential due to variations of the Earth rotation axis induces the crustal displacements due to pole motion. These displacements are observationally significant, while the displacements caused by variations in the rotation rate are negligible. The pole motion is characterized by three major components, namely the Chandler wobble, an annual term (annual wobble), and a secular motion (e.g., Lambeck 1980). Tenzer and Marinovich (2010) investigated the crustal displacements induced by pole motion in New Zealand over the period from 1962 to 2009. They found that the rate of crustal displacement induced by a secular pole motion was less than $0.1 \mathrm{~mm} /$ year over that period. The maximum horizontal motions due to the periodical variations of pole position (mainly attributed to the Chandler and annual wobble) were less than $4 \mathrm{~mm}$. The corresponding maximum vertical motions were larger by a factor of about 3 (up to $12.2 \mathrm{~mm}$ ). The summary of the maximum periodic and secular crustal deformations in New Zealand is given in Table 3.

\section{Summary and conclusions}

We have assessed the regional accuracy of the global ocean tide models TPXO7.2, GOT00.2, NAO.99b, FES2004, and EOT10a in New Zealand using the tide-gauge data from Wellington, Tauranga, Taranaki, Marsden Point, Jackson Bay, Timaru, and Port Charmers. The accuracy analysis revealed that TPXO7.2 provides the best solution for this part of the world.

The TPX07.2 global model has been further used to compute the ocean-tide loading vertical and horizontal displacements in New Zealand, adopting the mass loading Love numbers for the Gutenberg-Bullen A standard model of the Earth.

We have demonstrated that the ocean-tide loading exhibit different pattern than the generating ocean tide. Moreover, the ocean-tide loading is spatially very variable. For a given harmonic tidal constituent, the distribution of vertical displacements differs from the distribution of horizontal displacements. The phase distributions of vertical and horizontal displacements also differ significantly from each other. For example, the vertical displacement wave of the principal lunar semi-diurnal and larger lunar elliptic semi-diurnal components $M_{2} / N_{2}$ travels in the counterclockwise direction (similar to the generating $M_{2} / N_{2}$ tide) but the horizontal $\mathrm{M}_{2} / \mathrm{N}_{2}$ displacements propagate in the opposite -clockwise -- direction. Another observation is that the $\mathrm{M}_{2} / \mathrm{N}_{2}$ components of vertical displacements have amphidromes but their horizontal counterparts do not. We also note that the magnitude of ocean-tide loading is not simply decreasing function of the distance from the coast. Not only the points with the largest amplitudes but also those with the smallest displacements are located on the coast for all tidal harmonic constituents except for the vertical displacements of the larger lunar elliptic semi-diurnal constituent $\mathrm{N}_{2}$ (their minima are located to the north-west from Christchurch) as well as the meridional horizontal displacements of the lunar elliptic monthly long-period component $M_{m}$ (their minima are located along the strip that goes through central parts of the North and South Islands).

The major contribution to the vertical and horizontal ocean-tide 
loading displacements is attributed to the semi-diurnal and diurnal tidal harmonic constituents $\left(\mathrm{M}_{2}, \mathrm{~S}_{2}, \mathrm{~N}_{2}, \mathrm{~K}_{2}, \mathrm{~K}_{1}, \mathrm{O}_{1}, \mathrm{P}_{1}, \mathrm{Q}_{1}\right)$, while the contribution of the long-period tidal components $\left(M_{f}, M_{m}\right)$ and the shallow-water nonlinear components $\left(M_{4}, M S_{4}, M N_{4}\right)$ is to about $1 \mathrm{~mm}$ and $0.2 \mathrm{~mm}$, respectively. The maxima of the oceantide loading vertical displacements are situated in the Cape Reinga (upper north region of the North Island), where the amplitude of vertical displacements can reach $5.6 \mathrm{~cm}$ when all ocean-tide loading constituents are in phase. The corresponding horizontal displacements can reach to about $1.2 \mathrm{~cm}$ in the meridional and prime-vertical components. The maxima of horizontal displacements are near Nelson (northwest part of the South Island), where the amplitudes of the prime-vertical and meridional components of horizontal displacements can reach 1.3 and $1.6 \mathrm{~cm}$, respectively. The comparison of crustal displacements in New Zealand due to various factors indicates that the largest periodic motions up to several centimeters are due to the Earth tide. The second largest contribution is due to the ocean-tide loading. The maximum amplitudes of the ocean-tide loading are typically an order of magnitude larger than the maxima of the atmospheric loading displacements. The smallest displacements are due to the periodic pole motion. Among the long-term secular crustal motions in New Zealand, tectonic forces represent the largest contribution to horizontal rates reaching $3-5 \mathrm{~cm} /$ year. The largest vertical rates due to tectonic and (local) volcanic forces are mostly below $1 \mathrm{~cm} /$ year. The motions induced by the secular pole motion and due to the glacial isostatic adjustment in New Zealand are less than $1 \mathrm{~mm} /$ year.

\section{References}

Agnew D.C. (1996): SPOTL: Some programs for ocean-tide loading, SIO Ref. Ser. 96-8, 35 pp., Scripps Institution of Oceanography, La Jolla, CA.

Agnew D.C. (1997): NLOADF: a program for computing ocean-tide loading J. Geophys. Res., 102, 5109-5110.

Andersen O.B. (1995): Global Ocean Tides from ERS1 and TOPEX/POSEIDON Altimetry J. Geophys. Res., 100, 25249-25259.

Andersen O.B., Woodworth L.R. and Flather A. (1995): Intercomparison of Recent Ocean Tide Models J. Geophys. Res., 100, 25261-25282.

Andersen O.B., Egbert G., Erofeeva L. and Ray R.D. (2006a): Mapping non linear shallow-water tides: a look at the past and future Oc. Dyn. 56, 416-429.

Andersen O.B., Egbert G., Erofeeva L. and Ray R.D. (2006b): Non-linear tides in shallow water regions from multi-mission satellite altimetry and the Andersen 06 Global Ocean Tide Model In: AGU WPGM Meeting, Beijing, China, July.

Beavan J., Moore M., Pearson C., Henderson M., Parsons B., Bourne S., England P., Walcott D., Blick G., Darby D. and Hodgkinson K. (1999): Crustal deformation during 1994-1998 due to oblique continental collision in the central Southern Alps, New Zealand, and implications for seismic potential of the Alpine fault J Geophys. Res. Solid Earth, 104, B11, 25233-25255.

Beavan J. and Haines J. (2001): Contemporary horizontal velocity and strain rate fields of the Pacific-Australian plate boundary zone through New Zealand J. Geoph. Res., 106, 741-770.

Beavan J., Tregoning P., Bevis M., Kato T. and Meertens C. (2002): Motion and rigidity of the Pacific Plate and implications for plate boundary deformation J. Geoph. Res., 107, B10, ETG 19/1-15.

Beavan J., Matheson D., Denys P., Denham M., Herring T., Hager B. and Molnar P. (2004): A vertical deformation profile across the Southern Alps, New Zealand, from 3.5 years of continuous GPS Data Cahiers de Centre Europeen de Geodynamique et Seismologie, Proceedings of the Workshop: The state of GPS vertical positioning: Separation of earth processes by space geodesy, 24, 111-123.

Beavan J. Ellis S., Wallace L. and Denys P. (2007): Kinematic constraints from GPS on oblique convergence of the Pacific and Australian plates, Central South Island, New Zealand Geoph. Monograph., 175, 75-94.

Beavan J., Denys P., Denham M., Hager B., Herring T. and Molnar P. (2010): Distribution of present-day vertical deformation across the Southern Alps, New Zealand, from 10 years of GPS data, Geophys. Res. Lett., 37, L16305.

Bourne S., Arnadottir T., Beavan J., Darby D., England P., Parsons B., Walcott R. and Wood P. (1998): Crustal deformation of the Marlborough fault zone in the South Island of New Zealand: Geodetic constraints over the interval 1982-1994 J. Geoph. Res., $103,147-165$.

Bos M.S., Baker T.F., R囚thing K. and Plag H.-P. (2002): Testing ocean tide models in the Nordic seas with tidal gravity observations, Geophys. J. Intl., V150, 3, 687-694.

Bos M.S. and Baker T.F. (2005): An estimate of the errors in gravity ocean tide loading computations J. Geod., 79, 50-63.

Eanes R.J. (1994): Diurnal and semi-diurnal tides from TOPEX/POSEIDON altimetry Eos Trans. AGU, 75, 16, 108. 
Egbert G.D. and Erofeeva L. (2002): Efficient inverse modeling of barotropic ocean tides J. Atmos. Oceanic Technol., 19, 183-204.

Farrell W.E. (1972): Deformation of the Earth by surface loads Rev. Geophys. Space Phys. 10, 761-797.

Gladkikh V. and Tenzer R. (2010): Crustal deformations due to atmospheric pressure loading in New Zealand Presentation Abstracts, Active Earth Processes Workshop 2010, 18 November, 2010, Dunedin, New Zealand.

Goring D.G. and Walters R.A. (2002): Ocean-tide loading and Earth tides around New Zealand New Zealand Journal of Marine and Freshwater Research, 36 299-309.

Lambeck K. (1980): The Earth's Variable Rotation New York Cambridge University Press.

Letellier T. (2004): Etude des ondes de marée sur les plateux continentaux. Thèse doctorale, Université de Toulouse III, Ecole Doctorale des Sciences de I'Univers, de I'Environnement et de I'Espace, 237 pp. (in French)

Le Provost C., Lyard F., Genco M.L. and Rabilloud F. (1998): A hydrodynamic ocean tide model improved by assimilation of a satellite altimeter-derived data set J. Geophys Res., 103(C3), 5513-5529.

Lefevre F., Lyard F., Le Provost C. and Schrama E.J.O. (2002): FES99: a global tide finite element solution assimilating tide gauge and altimetric information Atmos Ocean Tech., 19, 1345-1356.

Lyard F., Lefevre F., Letellier T. and Francis O. (2006): Modelling the global ocean tides: modern insights from FES2004, Ocean Dynamics, 56, 394-415.

Manabe S., Sato T., Sakai S. and Yokoyama K. (1991): Atmospheric loading effect on VLBI observations, in Proceedings of the AGU Chapman Conference on Geodetic VLBI: Monitoring Global Change, NOAA Tech. Rep. NOS 137 NGS 49, 111-122.

Matsumoto K., Takanezawa T. and Ooe M. (2000): Ocean Tide Models Developed by Assimilating TOPEX/POSEIDON Altimeter Data into Hydrodynamical Model: A Global Model and a Regional Model Around Japan J. Oceanogr., 56, 567-581.

Peltier W.R. (2004): Global Glacial Isostasy and the Surface of the Ice-Age Earth: The ICE-5G (VM2) Model and GRACE, Ann. Rev. Earth and Planet. Sci., 32, 111-149.

Penna N.T., Bos M.S., Baker T.F. and Scherneck H.-G. (2008): Assessing the accuracy of predicted ocean tide loading displacement

VERSITA values, J Geod., 82, 893-907.

Petrov L.Y. (1998): VLBI Measurements of the Crustal Deformations Induced by Polar Motion Izvestiya, Physics of the Solid Earth 34, 228-230.

Rabbel W. and Zschau J. (1985): Static deformation and gravity changes at the earth's surface due to atmospheric loading, J. Geophys., 56, 81-99.

Rabbel W. and Schuh H. (1986): The influence of atmospheric loading on VLBI-experiments, J. Geophys., 59, 164-170.

Ray R.D. and Sanchez B.V. (1989): Radial deformation of the Earth by oceanic tidal loading, NASA Tech. Memo, 100743.

Ray R.D. (1999): A Global Ocean Tide Model From TOPEX/POSEIDON Altimetry: GOT99.2 NASA Technical Memorandum 209478.

Savcenko R. and Bosch W. (2008): EOT08a, empirical ocean tide model from multi-mission satellite altimetry Report 81, Deutsches Geodätisches Forschungsinstitut (DGFI), München.

Savcenko R. and Bosch W. (2010): EOT10a - a new global tide model from multi-mission altimetry, Conference abstracts, EGU General Assembly 2010, 2-7 May, 2010 in Vienna, Austria.

Scherneck H.-G. and Bos M.S. (2002): Ocean Tide and Atmospheric Loading IVS 2002 General Meeting Proceedings, 205-214.

Schwiderski E.W. (1980): On Charting Global Ocean Tides Rev. Geophys. Space Phys., 18, 1, 243-268.

Shum C.K., Woodworm P.L., Anderson O.B., Egbert G., Francis O., King C, Klosko S., Le Provost C, Li X., Molines J-M., Parke M., Ray R., Schlax M., Stammer D., Tierney C, Vincent P. and Wunsch C. (1997): Accuracy assessment of recent ocean tide models J. Geophys. Res., 102, 25173-25194.

Tenzer R., Denys P. and Stevenson M. (2009): A compilation of preliminary map of the vertical deformations in New Zealand from continuous GPS data, Session (3.4) Geodesy and Geodynamics: Global and Regional Scales: Geodesy, crustal motions and geodynamic processes, Geodesy for Planet Earth, Conference Abstracts, IAG Scientific Assembly, Buenos Aires, Argentina, August 31 to September 4, 2009.

Tenzer R. and Marinovich Y. (2010): A theoretical estimation of the Earth's crustal deformations in New Zealand induced by the polar motion Conference SKANZ 2010, February 16-18, 2010, Auckland, New Zealand. 


\section{Journal of Geodetic Science}

Thomas M. (2001): Ozeanisch induzierte Erdrotationsschwankungen - Ergebnisse eines Simultanmodells für Zirkulation und ephemeridische Gezeiten im Weltozean, Ph.D. Dissertation, Univ. of Hamburg, p. 129. (in German)

van Dam T.M. and Wahr J.M. (1987): Displacements of the Earth's surface due to atmospheric loading: Effects on gravity and baseline measurements, J. Geophys. Res., 92, 1281-1286.

Wallace L.M., Beavan J., McCaffrey R. and Darby D. (2004): Subduction Zone Coupling and Tectonic Block Rotations in the North Island, New Zealand., J. Geophys. Res. - Solid Earth, 109, B12.

Wallace L.M., Beavan J., McCaffrey R., Berryman K. and Denys P.
(2007): Balancing the Plate Motion Budget in the South Island, New Zealand Using GPS, Geological and Seismological Data, Geophys. J. Int., 168, 1, 332-352.

Walters R.A., Goring D.G. and Bell R.G. (2001): Ocean tides around New Zealand, New Zealand Journal of Marine and Freshwater Research, 35, 567-579.

Weis P. (2006): Ocean Tides and the Earth's Rotation - Results of a High-Resolving Ocean Model forced by the Lunisolar Tidal Potential Reports on Earth System Science, the Max-Planck-Institute of Meteorology, $36 \mathrm{p}$. 